\title{
A One-dimensional Land Surface Model Adaptable to Intensely Cold Regions and its Applications in Eastern Siberia
}

\author{
By Takeshi Yamazaki \\ Department of Geophysics, Graduate School of Science, Tohoku University, Sendai, Japan
}

(Manuscript received 4 January 2001, in revised form 15 July 2001)

\begin{abstract}
A one-dimensional land surface model has been developed to estimate water and energy fluxes between the atmosphere and ground surfaces. The model includes three submodels; vegetation, snow cover, and soil. In order to adapt the model to intensely cold regions, the snow cover submodel can consider depth hoar by means of effective temperature gradient. This submodel can calculate profiles of snow temperature, density, and liquid water content using meteorological data inputs; the model structure is simple having snow layers with the same thickness. The ratio of fallen snow amount to rain amount is given as a function of wet-bulb temperature.

The model has been applied to a GAME-Siberia site in the Central Yakutia, Russia. Since we do not have complete data sets in midwinter, the model has been validated through whole winter simulations at several routine stations first. Snow depth and snow-cover period are simulated reasonably. Next, fluxes have been estimated using 1998 data at the GAME plain taiga site, compared with the observed fluxes. Diurnal and seasonal changes of fluxes are simulated reasonably. The calculated snow cover disappearance date is earlier than the observed day.
\end{abstract}

\section{Introduction}

This study is a proposal of a one-dimensional model to estimate energy and water exchange at ground surfaces in mainly intensely cold regions. Many land surface schemes have been presented to be incorporated into general circulation models (GCMs), for example, BATS (Dickinson 1984), SiB (Sellers et al. 1986) and CLASS (Verseghy 1991; Verseghy et al. 1993). However, the main objective of the model presented in this paper is understanding land-surface processes through model implementation. Although the essence of this model is useful for land surface schemes incorporated into GCMs, incorporation into the GCMs is not the final goal.

\footnotetext{
Corresponding author: Takeshi Yamazaki, Department of Geophysics, Graduate School of Science, Tohoku University, Aza-Aoba, Aramaki, Aoba-ku, Sendai, 980-8578, Japan.

E-mail: yama@wind.geophys.tohoku.ac.jp (C)2001, Meteorological Society of Japan
}

The model in this study includes three submodels; vegetation, snow cover, and soil. In the vegetation submodel, the canopy is divided into a "crown space" and "trunk space" (without leaves), with the crown space subdivided into two layers. Heat balance is solved with respect to radiative, sensible, and latent heat fluxes among the atmosphere and the two crown layers. The snow cover submodel is a vertical one-dimensional multi-layer model; its structure and physical processes are very simple although it can calculate correct conductive heat in snow. Basic outputs are snow temperature, density, and water content. The soil submodel considers a heat conduction equation. Heat of fusion in frozen soil is taken account of with a method wherein heat capacity is regarded as larger in a small temperature range near the freezing point.

In intensely cold regions, snow cover forms 'depth hoar', because it is exposed to a large vertical temperature gradient. Depth hoar has general characteristics of low density and low thermal conductivity. Thus, it influences not only energy and 
water exchange between the atmosphere and ground, but soil freezing conditions (Zhang et al. 1996). Therefore, treatment of depth hoar is one of the keys for snow cover models in intensely cold regions. However, few models consider depth hoar to estimate energy and water exchange. The authors introduced effective temperature gradient as an index of depth hoar. Thermal conductivity and compactive viscosity coefficient are modified with it (Yamazaki 1998).

Input data are wind speed, air temperature, specific humidity (or water vapor pressure), precipitation, solar radiation, and downward atmospheric radiation. The ratio of snow amount to rain amount is given as a function of wet-bulb temperature, although rain and snow are usually distinguished by a certain threshold of air temperature. This model can be implemented with a personal computer.

The model has been applied to GAME-Siberia plain taiga site located in the Central Yakutia, Russia. The GAME (GEWEX Asian Monsoon Experiment) is one of the GEWEX (Global Energy and Water cycle EXperiment) continental projects, including four regional experiments in Asia. Tibet and Siberia belong to cold region in these regional experiments. With GAME-Tibet, Takayabu et al. (2001) compared performances of four land surface process models, which included this model (before minor improvement, described as TOHOKU model) with use of POP97 data.

Siberia, which includes permafrost, forest and seasonal snow cover, is one of the most interesting fields to validate a land surface model treating a cold region. In GAME-Siberia, IOP2000 has been planned to observe meteorological and hydrological components for various land surface conditions. Use of the model parameters defining energy and water fluxes will be studied. Although year-round simulation is ideal, high quality data has not been obtained yet in winter. Thus this paper will show validation of a snow submodel using routine meteorological data and simulation from spring to summer using data at a plain taiga site in 1998 as preliminary results to full-year calculation.

\section{Model}

The model is one-dimensional and includes the following three submodels. Spatial and time intervals are $\Delta z=0.02 \mathrm{~m}$ in snow, $\Delta z=0.1 \mathrm{~m}$ in soil, and $\Delta t=200 \mathrm{~s}$, respectively, in this study.

\subsection{The canopy submodel}

Details of this model and its performance have been described in Yamazaki et al. (1992). Heat storage term and canopy interception of rain are newly considered. The fluxes above and in the canopy can be calculated by use of this model if incident solar and infrared radiation, air temperature, specific humidity, and wind speed are given as input parameters. The canopy is divided into a "crown space" and "trunk space" (without leaves), with the crown space subdivided into two layers. Heat balance is solved with respect to radiative, sensible, and latent heat fluxes among the atmosphere and the two crown layers. Sensible and latent heat fluxes can be described as proportional to differences of temperature and specific humidity, respectively.

The heat-balance equation for each layer is

$$
C \frac{d T_{C i}}{d t}=S_{C i}+L_{C i}-H_{C i}-l E_{C i}, \quad(i=1,2) .
$$

Here, $S_{C i}$ and $L_{C i}$ are the net absorption of solar and infrared radiation, $H_{C i}$ and $l E_{C i}$ are the sensible and latent heat fluxes from the canopy elements to the surrounding air in the $i$ th layer. The left term is heat storage term added in this study, $C$ is heat capacity.

Since the fluxes must be continuous,

$$
\begin{aligned}
H_{C 1} & =H_{12}-H_{S}, \\
H_{C 2} & =H-H_{12}, \\
l E_{C 1} & =l E_{12}-l E_{S},
\end{aligned}
$$

and

$$
l E_{C 2}=l E-l E_{12} .
$$

Here, $H$ and $l E$ are sensible and latent heat fluxes from the top of the canopy layer to the atmosphere, $H_{12}$ and $l E_{12}$ are those between two canopy layers, and $H_{S}$ and $l E_{S}$ are those at the bottom of the canopy layer (equal to those over snow or soil surface), respectively.

The equation of interception water stored on the leaves, $M_{i}$, is

$$
\begin{aligned}
\frac{d M_{i}}{d t}=P_{C i}-D_{C i}-E_{w C i} / \rho_{w}, \\
\\
\left(i=1,2,0 \leq M_{i} \leq M_{\max }\right) .
\end{aligned}
$$

Here, $P_{C i}$ is intercepted rain $(=[1-\exp (-0.5 P A I)]$ $\times P r$, where $\operatorname{Pr}$ is precipitation), $D_{C i}$ shows water drainage rate, $E_{w} C_{i}$ is evaporation of intercepted 
precipitation, and $\rho_{w}$ is water density. The maximum interception water, $M_{\max }$, is obtained with the following equation (Kondo et al. 1992);

$$
M_{\max }=s_{\text {branch }} P A I_{\min }+s_{\text {leaf }}\left(P A I-P A I_{\min }\right) .
$$

Here, $P A I$ is plant area index and $P A I_{\min }$ is the minimum value of $P A I$. Since it shows the stem and branch area in deciduous forest, $P A I-P A I_{\text {min }}$ indicates only leaf area; $s_{\text {branch }}$ and $s_{\text {leaf }}$ are water storage capacity for the unit branch and leaf area index, respectively.

Evapotranspiration, $E_{C i}$, and evaporation, $E_{w C i}$, are as follows.

If the canopy is dry $\left(M_{i}=0\right)$,

$$
E_{C i}=\rho_{a} j_{i} c_{h}\left(a-a_{\min }\right) \delta_{i} U_{i}\left(q_{s a t}\left(T_{C i}\right)-q_{i}\right),
$$

and

$$
E_{w C i}=0,
$$

where $\rho_{a}$ is air density, $j_{i}$ shows the leaf evapotranspiration factor, $c_{h}$ is the transfer coefficient of individual leaves for sensible heat, $a$ shows plant-area density ( $=P A I / \delta, \delta$ : thickness of crown space), $a_{\min }=P A I_{\min } / \delta_{i}, \delta_{i}$ thickness of each canopy later, $U_{i}$ and $q_{i}$ are wind speed and specific humidity in each canopy layer, and $q_{\text {sat }}$ represents saturation specific humidity.

If the canopy is wet $\left(M_{i}>0\right)$,

$$
\begin{aligned}
E_{C i}=E_{w C i}= & \rho_{a} \operatorname{MAX}\left[j_{i}\left(a-a_{\min }\right), \frac{M_{i}}{M_{\max }} a\right] \\
& \times c_{h} \delta_{i} U_{i}\left(q_{s a t}\left(T_{C i}\right)-q_{i}\right) . \quad(10)
\end{aligned}
$$

Note that although transpiration is only from leaves, evaporation occurs not only from leaves but from stems and branches. When condensation occurs $\left(q_{i}>q_{s a t}\left(T_{C i}\right)\right), j_{i}$ is set to 1 :

$$
E_{C i}=E_{w C i}=\rho_{a} a c_{h} \delta_{i} U_{i}\left(q_{s a t}\left(T_{C i}\right)-q_{i}\right) .
$$

Evapotranspiration factor $j$ is written with use for stomatal resistance, $r_{s}$ :

$$
j=\frac{1}{1+c_{h} U r_{s}} .
$$

The following equation is used as stomatal resistance:

$$
r_{s}=r_{m}\left(1+S_{a b m} / S_{a b i}\right) \Omega \text {. }
$$

Here, $S_{a b i}$ is the shortwave radiation absorbed by a unit of leaf area in the $i$-th layer, which is calculated in the model; $r_{m}$ the minimum value of $r_{s}$, and $S_{a b m}$ the value of $S_{a b i}$ when $r_{s}=2 r_{m}$. The factor $\Omega$ expresses influence of air dryness:

$$
\Omega=1 /(1-b \delta e)
$$

where $\delta e$ is saturation deficit and $b$ is a coefficient depending on species.

\subsection{The snow-cover submodel \\ a. Basic equations}

The basic equation to solve in snow cover is as follows:

$$
\begin{aligned}
c_{\text {snow }} \rho_{\text {snow }} \frac{\partial T_{\text {snow }}}{\partial t} & =\frac{\partial}{\partial z}\left(\lambda_{\text {snow }} \frac{\partial T_{\text {snow }}}{\partial z}\right) \\
& -\frac{\partial I_{n}}{\partial z}-l_{f} F \quad(z>0)
\end{aligned}
$$

Here, $T_{\text {snow }}$ indicates snow temperature; $c_{\text {snow }}$, $\rho_{\text {snow, }}$ and $\lambda_{\text {snow }}$ are specific heat, density and thermal conductivity of snow; $t$ is time; $z$ is a vertical coordinate (downward positive); $l_{f}$ shows latent heat of fusion of ice; $F$ is the amount of snowmelt per unit time and volume (when $T_{\text {snow }}<0^{\circ} \mathrm{C}$, $F=0$ ); and $I_{n}$ is net solar flux in snow cover so that $I_{n}=(1-r)(1-A) S^{\downarrow} \exp (-\mu z)$. Here, $S^{\downarrow}$ is downward solar radiation; $r$ is absorptivity of solar radiation at the snow surface (cf. b.); $A$ represents albedo; and $\mu$ is the extinction coefficient of solar radiation set at $40 \mathrm{~m}^{-1}$ (Fukami et al. 1985).

\section{b. Boundary conditions}

For snow surfaces, heat balance equation with an infinitesimal thickness written as

$$
\begin{aligned}
r(1-A) S^{\downarrow} & +\epsilon\left(L^{\downarrow}-\sigma T_{s}^{4}\right) \\
& -H_{S}-l E_{S}+G_{0}=M,
\end{aligned}
$$

where $L^{\downarrow}$ shows downward longwave radiation; $T_{s}$ is snow surface temperature $(\mathrm{K}) ; \sigma$ is the StefanBoltzmann constant; $\epsilon$ indicates snow emissivity (= 0.97 , Kondo and Yamazawa (1986b)); $H_{S}$ and $l E_{S}$ are sensible and latent heat fluxes (upward positive); $G_{0}$ is conductive heat flux just beneath the snow surface; and $M$ represents heat of snowmelt at the snow surface (when $T_{s}<0^{\circ} \mathrm{C}, M=0$ ).

Snow albedo $A$ is given by an empirical equation using daily mean air temperature and daily precipitation amount based on Yamazaki et al. (1994) (see appendix). According to this method, one can estimate the albedo with an accuracy of 0.05 in 
midwinter and 0.1 in snowmelt season. Solar radiation absorptivity at the snow surface $r$ denotes that solar radiation is more absorbed as albedo decreases through accumulation of impurities at the surface. Therefore, $r$ is given as

$$
r=\frac{A_{\max }-A}{A_{\max }-A_{\min }}
$$

where $A_{\max }=0.88$ and $A_{\min }=0.4$.

Sensible and latent heat fluxes are written as

$$
H_{S}=c_{p} \rho_{a} C_{H} U\left(T_{s}-T_{a}\right),
$$

and

$$
l E_{S}=l \rho_{a} C_{E} U\left(q_{s a t}\left(T_{s}\right)-q_{a}\right)
$$

Here, $c_{p}, \rho_{a}$ are specific heat and density of air; $U, T_{a}, q_{a}$ are wind speed, air temperature, specific humidity; $l$ shows latent heat of evaporation or sublimation; $C_{H}$ and $C_{E}$ are bulk coefficients for sensible and latent heat set at $C_{H}=0.002$ and $C_{E}=0.0021$ (Kondo and Yamazawa 1986a). Snow mass change due to evaporation, condensation or sublimation is considered from calculated latent heat flux with Eq.(19).

The heat balance equation at the bottom of snow is

$$
G_{\text {soil }}-\lambda_{\text {snow }} \frac{\partial T_{\text {snow }}}{\partial z}=M_{B}
$$

Here, $G_{\text {soil }}$ is conductive heat from soil and $M_{B}$ is heat of snowmelt at the bottom.

Equation (15) is solved numerically by the CrankNicolson method. The detailed procedure for calculating temperature and water content is described in Yamazaki (1998).

\section{c. Effective temperature gradient and depth hoar formation}

Depth hoar is caused by vapor transport due to temperature gradient in snow cover. According to Colbeck (1983), highly faceted crystals grow in snow covers with temperature gradients larger than $10-20^{\circ} \mathrm{C} \mathrm{m}^{-1}$; the crystal growth rate is described by the product of temperature gradient $\Gamma$, diffusion coefficient of water vapor $D_{v}$, differential coefficient of saturated vapor density with respect to temperature $\delta$, and factors depending on snow particle size and separation. Values of $D_{v}$ and $\delta$ decrease as temperature decreases. Thus, crystals grow rapidly in snow covers with high temperature, other conditions being equal. Therefore, the following effective temperature gradients from tem- perature dependent parts are defined as:

$$
\left.\begin{array}{ll}
g_{t}(z, t)=\Gamma f\left(T_{\text {snow }}\right) & \left(\Gamma \geq 10^{\circ} \mathrm{C} \mathrm{m}^{-1}\right) \\
g_{t}(z, t)=0 & \left(\Gamma<10^{\circ} \mathrm{C} \mathrm{m}^{-1}\right)
\end{array}\right\}
$$

Here, $\Gamma=\left|\partial T_{\text {snow }} / \partial z\right| ;$ and

$$
\begin{aligned}
f(T)= & \frac{D_{v}(T)}{D_{v}\left(T_{0}\right)} \frac{\delta(T)}{\delta\left(T_{0}\right)} \\
& \simeq 1+0.0733 T+0.00197 T^{2}+0.0000187 T^{3} \\
& \left(-40^{\circ} \mathrm{C} \leq T \leq 0^{\circ} \mathrm{C}, T_{0}=0^{\circ} \mathrm{C}\right)
\end{aligned}
$$

Figure 1 shows dependence of $f$ on temperature.

As an index of depth hoar formation, the integrated value of $g_{t}$ is used:

$$
G_{t}(z, t+\Delta t)=G_{t}(z, t)+g_{t} \cdot \Delta t .
$$

However, the value of $G_{t}$ is reset to zero when water content exceeds $90 \%$ of maximum (cf.,e.) in a certain layer. Values of compactive viscosity coefficient and thermal conductivity are corrected if the value of $G_{t}$ reaches a threshold (cf.,f. and g.).

\section{d. The ratio of snowfall and rainfall}

According to analysis by Sugaya (1991), the authors have proposed the following equation for the ratio of the snow amount to total precipitation, $s$, as:

$$
\left.\begin{array}{r}
s\left(T_{W}\right)=1-0.5 \exp \left(-2.2\left(1.1-T_{W}\right)^{1.3}\right) \\
s\left(T_{W}\right)=0.5 \exp \left(-2.2\left(T_{W}-1.1\right)^{1.3}\right) \\
\left(T_{W}<1.1^{\circ} \mathrm{C}\right) \\
\left(T_{W} \geq 1.1^{\circ} \mathrm{C}\right)
\end{array}\right\},
$$

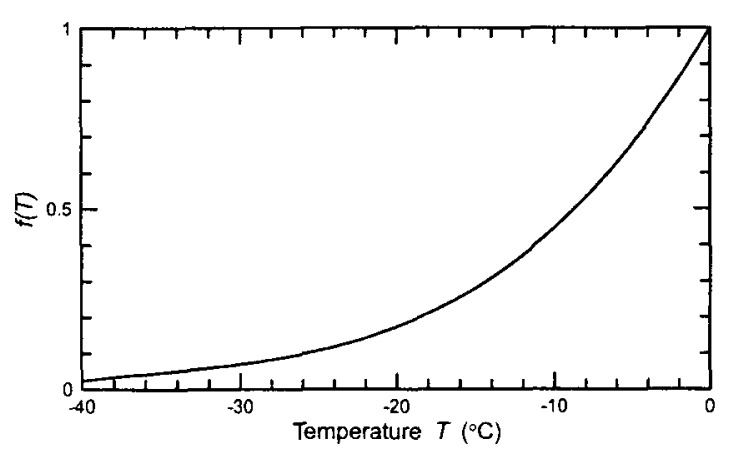

Fig. 1. Temperature dependency of effective temperature gradient $f$. 


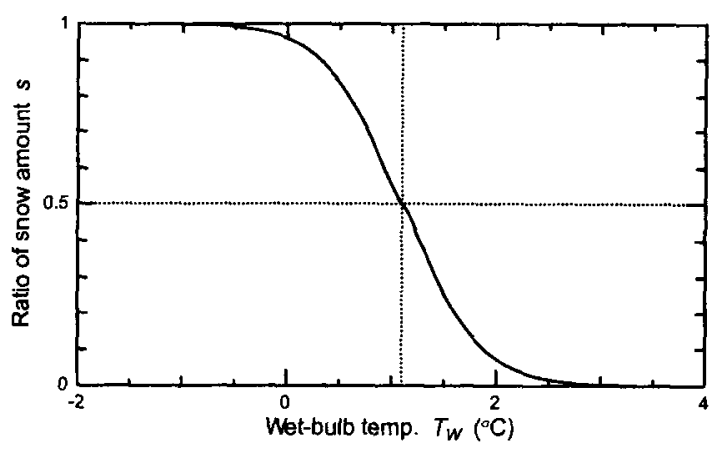

Fig. 2. Relationship between the ratio of snowfall amount and wet-bulb temperature.

(Fig. 2). Thus, the amount of snowfall is given as $s P_{r}$ and rain is $(1-s) P_{r}$. Wet-bulb temperature, $T_{W}$, can be approximated near $1^{\circ} \mathrm{C}$ as

$$
T_{W}=0.584 T_{a}+0.875 e-5.32,
$$

where $e$ is water vapor pressure (hPa).

\section{e. Liquid water flow}

Since the liquid water flow process is outside the main objectives, it is treated very simply in this model as follows. We set $\rho_{l \text { wmax }}$ as the maximum water amount in each layer; water exceeding $\rho_{\text {lwmax }}$ flows into the next lower layer. Then analysis proceeds one by one from the top layer. Maximum water content $w_{\max }\left(=\rho_{\text {lwmax }} / \rho_{\text {snow }}\right)$, is 0.1 , but it is set to 0.2 for $z \leq 0.05 \mathrm{~m}$. Maximum water content only near the surface is set large because water content beyond 0.2 is often observed in snowmelt season and this liquid water does not always drain, but refreezes according to cool conditions.

\section{f. Viscous compression}

Viscous compression of snow cover is calculated as

$$
\frac{\partial \rho_{d r y}}{\partial t}=\frac{W}{\eta} \rho_{d r y}
$$

Here, $\rho_{d r y}$ represents dry density of snow cover $(=$ $\left.\rho_{\text {snow }}-\rho_{l w}\right)$ while $W$ is overburden snow load; and $\eta$ is the compactive viscosity coefficient.

The compactive viscosity coefficient of snow except depth hoar, $\eta_{n d h}$, is given as in Yamazaki et al. (1993). That is,

$$
\eta_{n d h}=a_{v}(w) \eta_{0} \exp \left(K \rho_{d r y}-\alpha_{s} T_{\text {snow }}\right),
$$

where $\eta_{0}=6.9 \times 10^{5} \mathrm{~kg} \mathrm{~s} \mathrm{~m}^{-2}, K=2.1 \times 10^{-2}$ $\mathrm{m}^{3} \mathrm{~kg}^{-1}$, and $\alpha_{s}=9.58 \times 10^{-2}{ }^{\circ} \mathrm{C}^{-1}$ are constants (Kojima 1957; Shinojima 1967). The factor $a_{v}$ describes decrease of the compactive viscosity coefficient due to liquid water, assumed as

$$
a_{v}(w)=\frac{\exp \left(-\beta_{s} w\right)-\exp \left(-\beta_{s}\right)}{1-\exp \left(-\beta_{s}\right)} .
$$

Here, $w$ is water content and $\beta_{s}=18$.

The value of compactive viscosity coefficient of depth hoar is larger than that of rounded grains with equal density. Therefore, when the value of $G_{t}$ introduced in $c$. is in a transitional region, it is assumed that the value of $\eta$ increases linearly as

$$
\begin{gathered}
\eta=\eta_{n d h} \quad\left(G_{t}<G_{t 0}\right), \\
\eta=\frac{\left(f_{v}-1\right) G_{t}+G_{t v}-f_{v} G_{t 0}}{G_{t v}-G_{t 0}} \eta_{n d h} \\
\left(G_{t 0} \leq G_{t}<G_{t v}\right), \\
\eta=f_{v} \eta_{n d h} \quad\left(G_{t v} \leq G_{t}\right) .
\end{gathered}
$$

Here, constants are $G_{t 0}=1 \times 10^{7}{ }^{\circ} \mathrm{C} \mathrm{m}^{-1} \mathrm{~s}(=1.2$ ${ }^{\circ} \mathrm{C} \mathrm{cm}^{-1}$ day), $G_{t v}=4 \times 10^{7}{ }^{\circ} \mathrm{C} \mathrm{m}^{-1} \mathrm{~s}(=4.8$ ${ }^{\circ} \mathrm{C} \mathrm{cm}^{-1}$ day), and $f_{v}=10$. The constant $G_{t 0}$ is the value of $G_{t}$ when influence of depth hoar formation begins to appear; it was determined as the value when the increase of average diameter is $0.0005 \mathrm{~m}$ in experiments of Fukuzawa and Akitaya (1991). Moreover, $G_{t v}$ and $f_{v}$ were determined according to results of field experiments done by Kojima (1956).

After calculation of density with (27), snow cover is redivided into layers having the same thickness $(\Delta z)$.

\section{g. Thermal conductivity}

Thermal conductivity of snow excepting depth hoar, $\lambda_{n d h}\left(\mathrm{Wm}^{-1} \mathrm{~K}^{-1}\right)$, is given as one of the simplest functions of snow density, $\rho_{\text {snow }}\left(\mathrm{kg} \mathrm{m}^{-3}\right)$ :

$$
\lambda_{n d h}=0.029\left(1+10^{-4} \rho_{\text {snow }}{ }^{2}\right) .
$$

Thermal conductivity decreases when depth hoar is formed; a similar relationship to compactive viscosity can be used:

$$
\begin{array}{r}
\lambda_{\text {snow }}=\lambda_{n d h} \quad\left(G_{t}<G_{t 0}\right), \\
\lambda_{\text {snow }}=\frac{\left(f_{t}-1\right) G_{t}+G_{t t}-f_{t} G_{t 0}}{G_{t t}-G_{t 0}} \lambda_{n d h} \\
\left(G_{t 0} \leq G_{t}<G_{t t}\right),
\end{array}
$$




$$
\lambda_{\text {snow }}=f_{t} \lambda_{\text {ndh }} \quad\left(G_{t t} \leq G_{t}\right) .
$$

Here, $G_{t t}=1 \times 10^{8}{ }^{\circ} \mathrm{Cm}^{-1} \mathrm{~s}\left(=12^{\circ} \mathrm{Ccm}^{-1}\right.$ day $)$ and $f_{t}=0.3$ (refer to Sturm and Johnson (1992)).

\subsection{The soil submodel}

Soil layers require an equation similar to (15), but not including second and third terms:

$$
c_{\text {soil }} \rho_{\text {soil }} \frac{\partial T_{\text {soil }}}{\partial t}=\frac{\partial}{\partial z}\left(\lambda_{\text {soil }} \frac{\partial T_{\text {soil }}}{\partial z}\right) \quad(z>0) .
$$

Heat of fusion of frozen soil is taken into account with a method where heat capacity is regarded as larger in a small temperature range near the freezing point (Fukuda and Ishizaki 1980). Presently, movement of liquid water in soil is not accounted for in this model. At the bottom boundary of soil layers (10 m depth), soil temperature is fixed at a climatic annual mean value.

When no snow cover exists, the heat balance equation at the soil surface,

$$
(1-A) S^{\downarrow}+\epsilon\left(L^{\downarrow}-\sigma T_{s}^{4}\right)-H_{S}-l E_{S}+G_{0}=0,
$$

should be considered (cf., Eq.(16)). Here, $H_{S}$ and $l E_{S}$ are fluxes over the soil surface; they are written similarly to Eqs.(18) and (19), but $C_{E}$ is replaced by $\beta_{\text {soil }} C_{H}\left(\beta_{\text {soil }}\right.$ : moisture availability).

\section{Snowcover simulation}

Since complete data sets in midwinter are unavailable, the model's ability to simulate temporal snowcover change using a routine data set was examined first. The data set is the baseline meteorological data set for GAME-Siberia. This data set includes daily mean, maximum and minimum air temperature, precipitation amount, water vapor pressure, maximum wind speed, duration of sunshine, snow depth, and other elements at 15 stations in the Lena River basin from 1986 to 1994. Monthly mean soil temperature is also used as an initial condition and for model validation (Takata 1998). Solar radiation and downward atmospheric radiation are estimated from duration of sunshine using experimental equations of Kondo et al. (1991). Diurnal variation of air temperature is considered to be a typical pattern fixed by observed daily mean, maximum, and minimum air temperatures.

Figure 3 shows simulated and observed snow depth at Yakutsk using raw precipitation data. In this figure, the dashed line denotes the calculation including depth hoar, while the dotted line shows calculated values ignoring depth hoar. Calculated snow depth including depth hoar is slightly overestimated, but the shape of time, series and period of snow season are well simulated. If the precipitation amount is corrected with catch efficiency of precipitation gauge (Kondo and Xu 1996), as a function of wind speed, the estimated snow depth

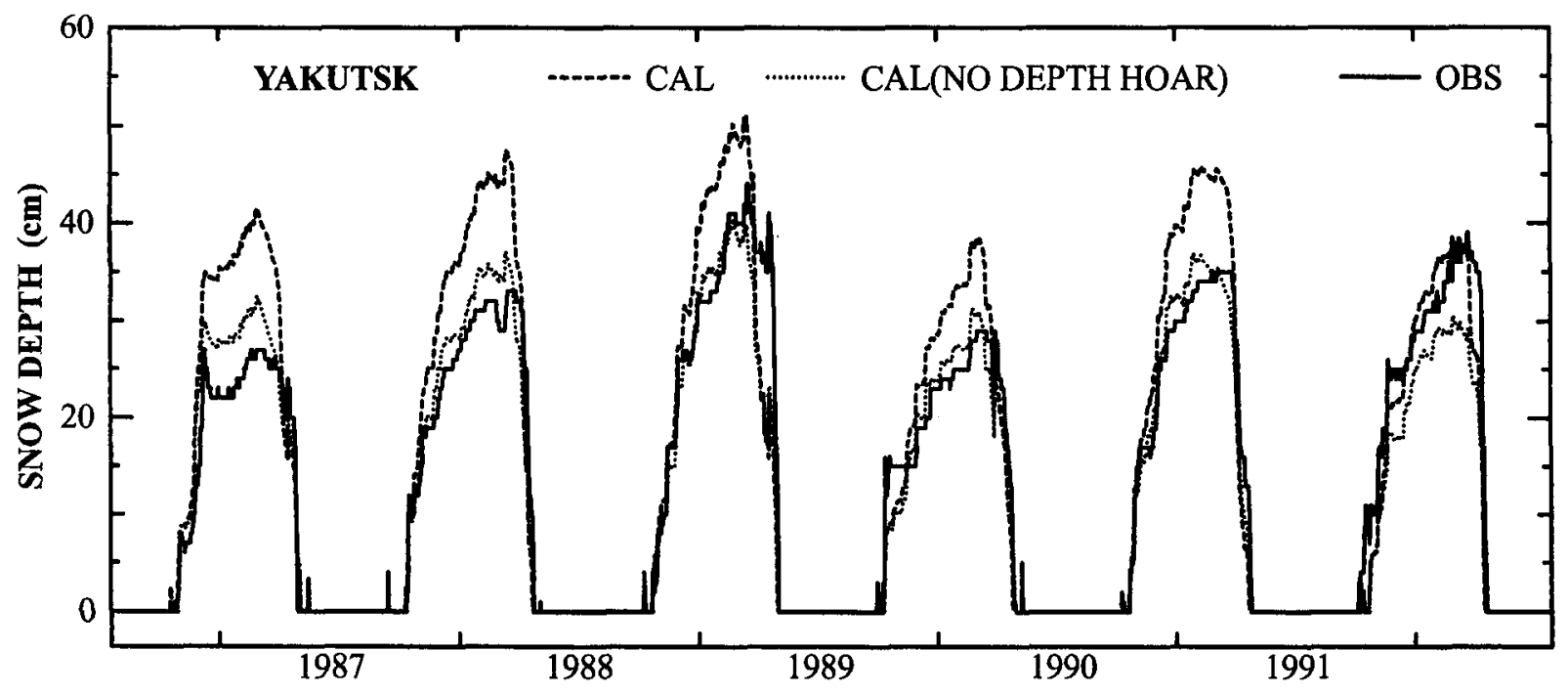

Fig. 3. Estimated and observed snow depth. 
becomes about two times as high as observed phenomena (figures are omitted). It is not clear why non-corrected estimation corresponds better.

On the other hand, calculated snow depth without depth hoar effects well corresponds to observation. However, one cannot conclude that simu-

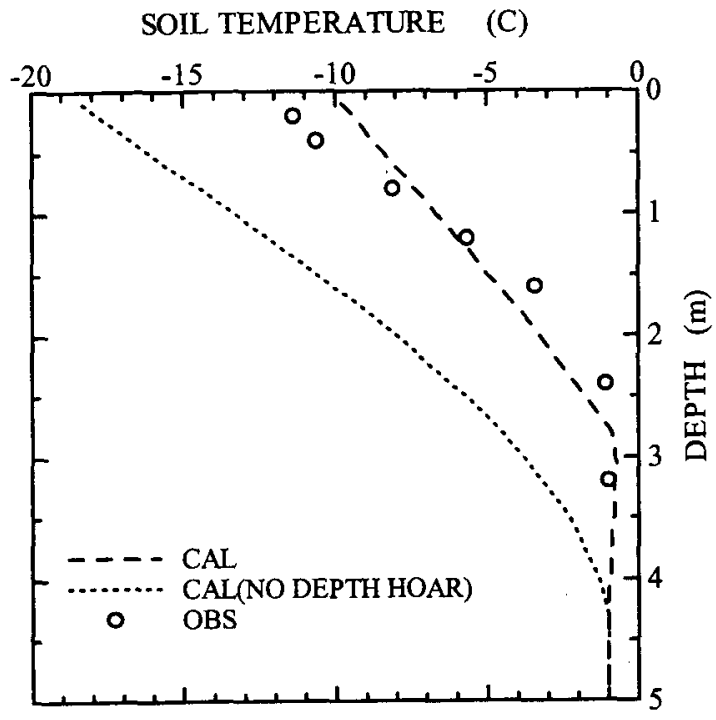

Fig. 4. Calculated soil temperature profile in February, 1988 with observed monthly mean soil temperature. lation without depth hoar is better than full simulation including depth hoar. Figure 4 displays the calculated soil temperature profile in February 1988 with observed monthly mean soil temperature. One observes that if depth hoar is not considered, calculated soil temperature is unrealistically low. Although soil loses heat through snow cover to the atmosphere in winter, the amount of heat loss is too great in no-depth hoar calculation because of high thermal conductivity of the snow. After all, full simulation including depth hoar is acceptable. Snow cover, especially depth hoar, works as a good heat insulator to partially control permafrost growth.

Figure 5 shows a simulated snow type at Yakutsk. Depth hoar is well formed in lower layers from the early snow season (October). One can find mature depth hoar in the lower third of overall snow cover and can find not mature but faceted particles in the middle third. Just before the snowmelt season (March), snow near the top surface also becomes faceted particles.

Sensible heat flux is usually downward in the snow cover period, the mean value is about 50 $\mathrm{Wm}^{-2}$. On the other hand, latent heat flux is near zero in midwinter and $20 \mathrm{Wm}^{-2}$ upward $(0.7$ $\mathrm{mm} \mathrm{d}^{-1}$ of evaporation) in the snowmelt season.

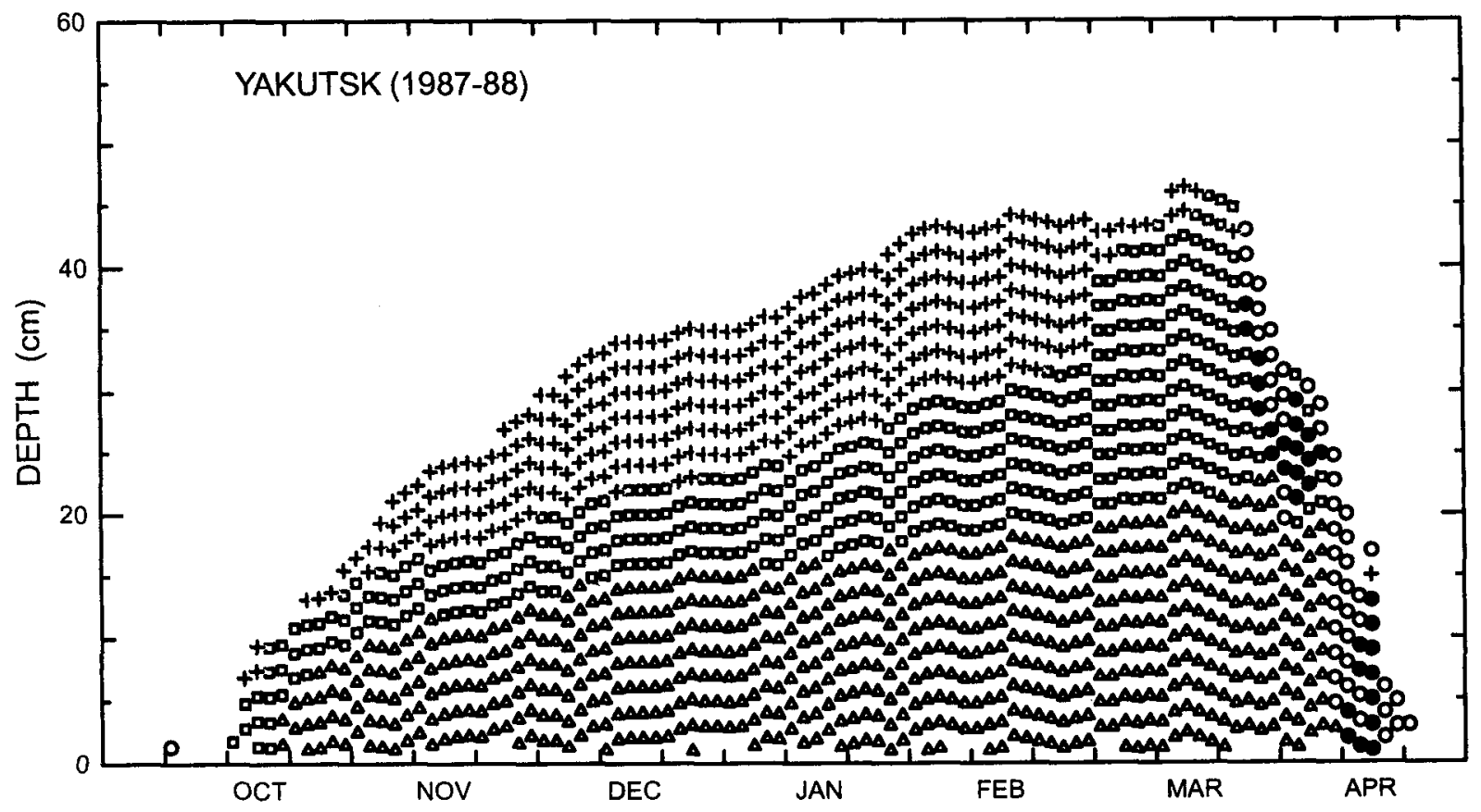

Fig. 5. Estimated snow types: $O$, wet snow $(w>0.01) ; \Delta$, depth hoar $\left(G_{t}>4 \times 10^{7 \circ} \mathrm{Cm}^{-1} \mathrm{~s}\right) ; \square$, faceted particle $\left(1 \times 10^{7}{ }^{\circ} \mathrm{Cm}^{-1} \mathrm{~s}<G_{t} \leq 4 \times 10^{7}{ }^{\circ} \mathrm{Cm}^{-1} \mathrm{~s}\right)$; + , new snow $\left(\rho<150 \mathrm{~kg} \mathrm{~m}^{-3}\right)$; and $\bigcirc$, other types. 


\section{Simulation at the GAME-Siberia site}

\subsection{Data and parameters}

The model has been applied to a plain taiga site of GAME-Siberia near Yakutsk City, Russia $\left(62^{\circ} \mathrm{N}, 130^{\circ} \mathrm{E}\right)$. The observation site is in a larch forest (mean stand height $18 \mathrm{~m}$ ), and a $32 \mathrm{~m}$ high tower is installed to observe one-dimensional water and heat exchange. Observed items are shortwave radiation, longwave radiation, net radiation, air temperature, humidity, wind speed, radiative temperature, sensible heat flux, ground heat flux, and precipitation (including throughfall and stem flow). More detailed description of the site can be found in Hiyama et al. (2001) and Ohta et al. (2001)

Table 1 shows the value of model parameters in this simulation. Parameters on canopy water storage, $s_{\text {branch }}$ and $s_{\text {leaf }}$, were fixed according to in situ experiments in 1996. Plant area index, $P A I$, was set to 0.8 before $27 \mathrm{May}$ and 1.2 after 6 June; it was assumed to increase linearly in the leaf opening period. Parameters related to stomatal resistance, $r_{m}$ and $S_{a b m}$, were fixed as diurnal variations of heat fluxes corresponded to observations (see next subsection). The parameter in Eq.(14), b, was given on referring to an analysis at the site (Tanaka 1999). Since no water movement was considered in the soil layer, all soil parameters in the table were set to match assumed soil mois-

Table 1. Parameter values in this simulation. See text for details.

\begin{tabular}{lll}
\hline parameter & symbol & value \\
\hline Canopy & & \\
Canopy heat capacity & $C$ & $250 \times P A l \mathrm{~J} \mathrm{~m}^{-2} \mathrm{~K}^{-1}$ \\
Branch water storage capacity & $s_{\text {branch }}$ & $1.1 \mathrm{~mm}$ \\
Leaf water storage capacity & $s_{\text {leaf }}$ & $0.15 \mathrm{~mm}$ \\
Canopy height & $h$ & $18 \mathrm{~m}$ \\
Canopy layer bottom height & $h_{1}$ & $9 \mathrm{~m}$ \\
Plant area index & $\mathrm{PAI}$ & $0.8-1.2$ \\
Minimum stomatal resistance & $r_{m}$ & $50 \mathrm{~s} \mathrm{~m}^{-1}$ \\
Stomatal parameter on solar radiation & $S_{\text {abm }}$ & $150 \mathrm{~W} \mathrm{~m}^{-2}$ \\
Parameter for influence of air dryness & $b$ & $0.027 \mathrm{~b} \mathrm{an}^{-1}$ \\
Soil & & \\
Volumetric soil moisture & & 0.2 \\
Saturation soil moisture & & 0.5 \\
Surface moisture availability & $\beta_{\text {soil }}$ & 0.3 \\
Thermal conductivity of soil & $\lambda_{\text {ooil }}$ & $1.0 \mathrm{~W} \mathrm{~m}^{-1} \mathrm{~K}^{-1}$ (frozen) \\
& & $0.8 \mathrm{~W} \mathrm{~m}^{-1} \mathrm{~K}^{-1}$ (unfrozen) \\
\hline
\end{tabular}

ture $(=0.2)$. Other parameters, independent of site, were set as described in Section 2.

\subsection{Diurnal variation}

Figure 6 displays comparison of observed and calculated diurnal variation of heat fluxes. For observed diurnal variation, refer to Hiyama et al.
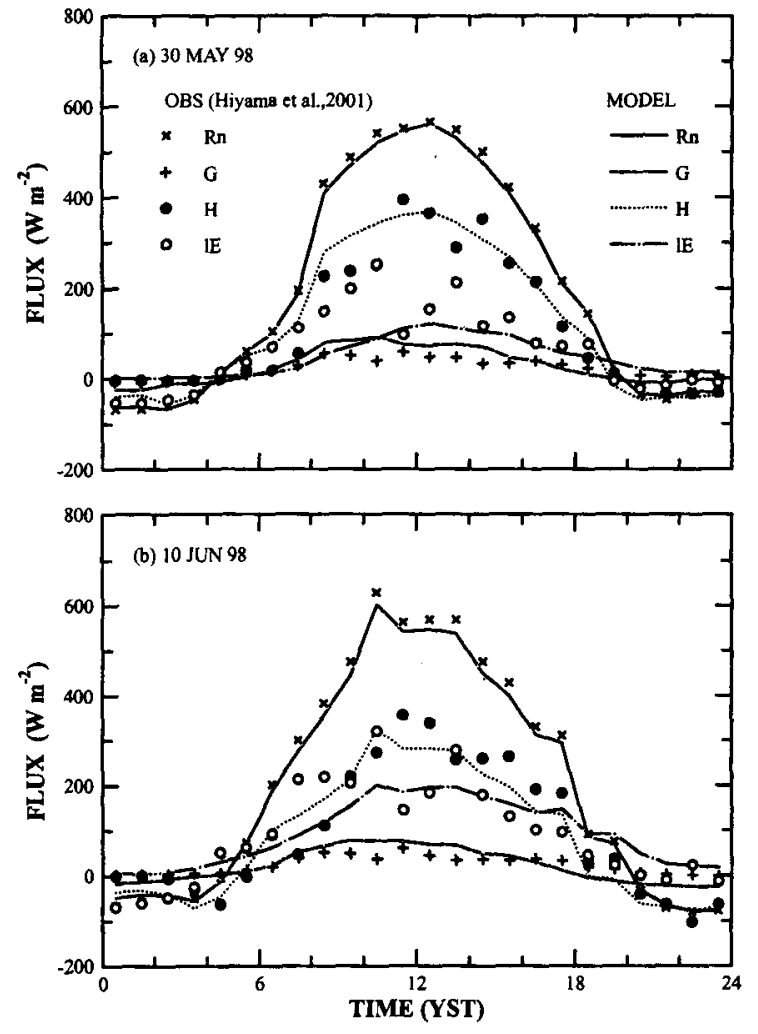

Fig.6. Comparison of observed and calculated diurnal variation of heat fluxes at the plain taiga site. (a) 30 May 1998 and (b) 10 June 1998.

(2001); note that observed latent heat flux was obtained as the residual from the energy balance equation. Figure 6(a) shows the result of 30 May 1998 when half of the leaves opened. On the other hand, Fig. 6(b) shows that of 10 June 1998 when all leaves had already opened. Simulated fluxes almost correspond with observations on both dates. However, simulated latent heat fluxes are smaller than observed fluxes in the morning. One reason is that the observed latent heat flux includes heat storage in the canopy and air because it is obtained as the residual. However, since heat storage is included in the term $G$ in calculation, the magnitude is less than $100 \mathrm{Wm}^{-2}$. Therefore, another reason should exist; one example is energy imbalance, which will be discussed in the next sub-section.

\subsection{Seasonal variation}

Figure 7 shows calculated seasonal variation of heat fluxes. In the snowmelt season (left arrow), heat flux into the ground, $G$, includes energy to 


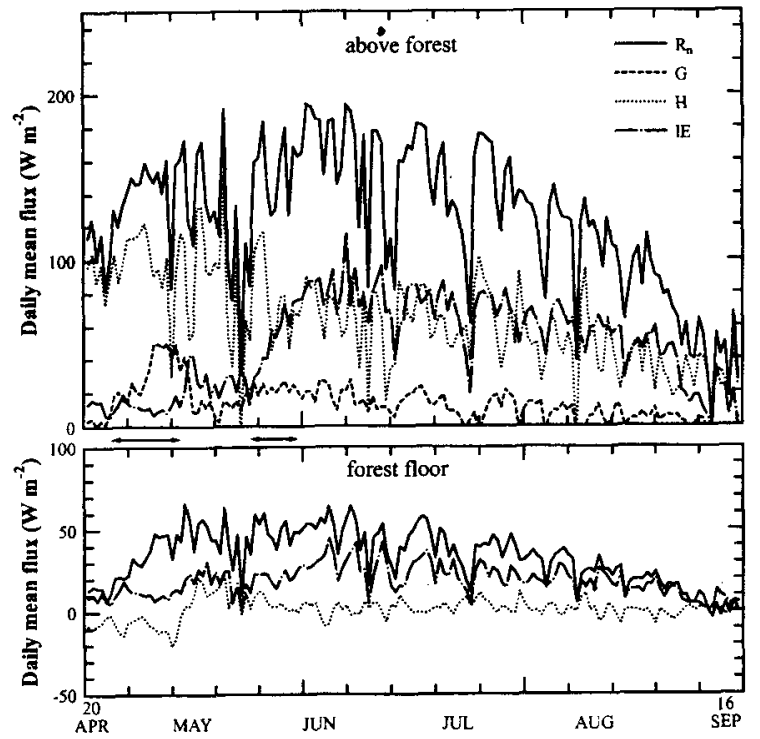

Fig. 7. Calculated seasonal variation of heat fluxes at the plain taiga site in 1998 .

Table 2. Comparison of calculated and observed water balance from 21 April to 7 September 1998.

\begin{tabular}{lcc}
\hline & model & obs. (Ohta et al. 2001) \\
\hline$P r$ & - & $106 \mathrm{~mm}$ \\
$P r+$ snow & - & $211 \mathrm{~mm}$ \\
$E_{\text {total }}$ & $248 \mathrm{~mm}$ & $151 \mathrm{~mm}$ \\
$E_{\text {total }}(6 / 4-9 / 7)$ & $215 \mathrm{~mm}$ & $128 \mathrm{~mm}$ \\
$E_{\text {under }}(6 / 4-9 / 7)$ & $71 \mathrm{~mm}$ & $45 \mathrm{~mm}$ \\
$E_{\text {under }} / E_{\text {total }}$ & 0.33 & 0.35 \\
$E_{\text {tntercept }} / P r$ & 0.22 & 0.15 \\
\hline
\end{tabular}

melt snow; most incident energy is changed to sensible heat (almost no latent heat). Sensible heat flux on the forest floor is downward in this season, so it contributes to snowmelt. In the opening leaves season (right arrow), latent heat increases and sensible heat decreases rapidly not only because of increasing plant activity, but also temperature dependency of the Bowen ratio. Air temperature changes from $0^{\circ} \mathrm{C}$ to $25^{\circ} \mathrm{C}$ in this season. These general features of seasonal variation correspond to observations (Ohta et al. 2001) except for sensible heat on the forest floor (no data).

Next, water balance will be compared with observations (Ohta et al. 2001) quantitatively. Table 2 indicates calculated and observed water balance in the warm period of 1998 . Total water input is indicated as $\mathrm{Pr}+$ Snow in the table. Calculated evapotranspiration using the model exceeds that observed. One reason is that heat balance $\left(R_{n}-G=H+l E\right)$ is satisfied exactly in the model. However, the observed energy budget is not closed; actually, it should be said that the heat-balance equation, which should be used at the surface of $z=0$, is not satisfied because the energy must be conserved. For example, Lee (1998) pointed out the necessity of a term related to non-zero vertical velocity for energy balance over tall vegetation. The relationship among observed fluxes is $H+l E=0.75\left(R_{n}-G\right)$ at this site (Ohta et al. 2001). This kind of "energy imbalance" has been reported in many cases over forests (Verma et al. 1986; Lee and Black 1993; Kelliher et al. 1997). Since observed evapotranspiration is 0.6 times the calculated value, this reason is insufficient. Another possible reason is that aging of leaves and repression by soil dryness are not considered in the model. The ratio of understory evapotranspiration, $E_{\text {under }}$, to total evapotranspiration, $E_{\text {total }}$, is well simulated with the model. This means that the forest floor role in the whole forest is correct in this model. Moreover, the ratio of interception, $E_{\text {intercept }} / P_{r}$, is slightly over-estimated in comparison to observation, but it can be said that the interception is reasonable despite its very simple parameterization of interception.

\subsection{Snowmelt}

Figure 8 shows comparison of calculated snow depth with observation (Hashimoto et al. 2001). The calculated snow disappearing date with meteorological data over forests (solid line) is earlier than observation by 3 days. According to the observation, snow temperature was below $0^{\circ} \mathrm{C}$ in the

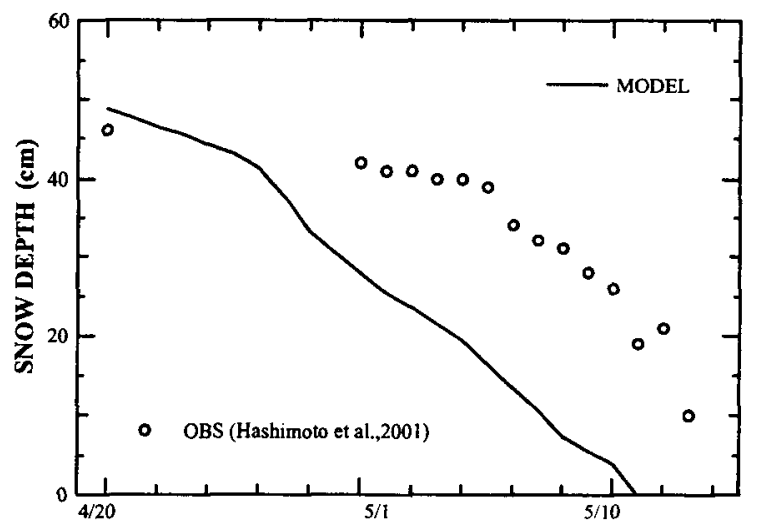

Fig. 8. Comparison of observed and calculated snow depth at the plain taiga site in 1998. 
Table 3. Sensitivity test for the snow submodel. Maximum water content $w_{\max }$ and bulk coefficient $C_{H}$ are changed. $C_{E}$ is also changed with the ratio of $C_{E} / C_{H}=1.05$. - denotes the same as standard condition.

\begin{tabular}{lccrr}
\hline & $\begin{array}{c}w_{\max } \\
(z \geq 0.05 \mathrm{~m})\end{array}$ & $\begin{array}{c}w_{\max } \\
(z<0.05 \mathrm{~m})\end{array}$ & $\mathrm{C}_{H}$ & $\begin{array}{r}\text { snow } \\
\text { disappearing }\end{array}$ \\
\hline standard & 0.1 & 0.2 & 0.002 & $11 \mathrm{May}$ \\
\hline$w_{\max }$ & 0.05 & 0.1 & - & $9 \mathrm{May}$ \\
& 0.2 & 0.4 & - & $24 \mathrm{May}$ \\
& - & 0.1 & - & $10 \mathrm{May}$ \\
& - & 0.4 & - & $24 \mathrm{May}$ \\
& 0.2 & - & - & $11 \mathrm{May}$ \\
\hline$C_{H}$ & - & - & 0.005 & $11 \mathrm{May}$ \\
\hline
\end{tabular}

layer deeper than $10 \mathrm{~cm}$ in April. That is to say, if snow is melting in the daytime, the melt water is refrozen at night. However, the $0^{\circ} \mathrm{C}$ layer at the top of the snow cover becomes deeper day by day in the calculation.

In order to examine the reason for rapid snow disappearance, it was simulated with meteorological data observed in the forest (on the forest floor); discrepancy of snow disappearance is halved, implying that delay occurs for two reasons. One is estimation of meteorological conditions in the forest; in fact, calculated net radiation on the forest floor is too large, perhaps because of downward longwave radiation. The other reason is the snow model itself.

Snow submodel sensitivity of snowmelt to maximum water content and bulk coefficients was tested (Table 3). It was found that the snowmelt was very sensitive to maximum water content near the surface $(z<0.05 \mathrm{~m})$. Thus, one must choose maximum water content carefully and investigate liquid water flow processes. On the other hand, the snow disappearance date is not changed if the bulk coefficient, $C_{H}$, equals 0.005 . When $C_{H}$ is large, snowmelt is rapid in the snowmelt season, but snow decreases slowly before the snowmelt season, perhaps due to low surface temperature from enhanced evaporation.

\section{Summary}

A one-dimensional model has been developed to estimate water and energy fluxes above ground particularly in intensely cold regions. The model can address depth hoar by means of effective temperature gradient which is newly introduced in this study. Due to consideration of depth hoar, reasonable soil temperature can be calculated under snow cover. Thus it is important to treat depth hoar for long term simulations including soil layers. The model simulates the character of diurnal and seasonal variation of fluxes at the GAMESiberia plain taiga site. However, flux magnitudes are greater than those observed; thus one must investigate "energy imbalance" over vegetation. In the snowmelt season, snow cover disappears earlier in model calculation. One should improve liquid water flow processes for snow cover and water movement in soil layers in the model.

\section{Acknowledgments}

This study is a part of the GAME-Siberia project. We would thank Prof. T. Yasunari of University of Tsukuba, Prof. Y. Fukushima of Research Institute for Humanity and Nature, Prof.T. Ohata of Hokkaido University, and Prof. B. Ivanov of Institute for Biological Problems of Cryolithozone, for giving us the opportunity to investigate in Siberia. We would also thank members of the GAMESiberia project, especially Prof. T. Ohta of Nagoya University, Dr. T.C. Maximov of Institute for Biological Problems of Cryolithozone, Dr. T. Hiyama of Nagoya University and Prof. T. Hashimoto of Shimane University, for their suggestions and cooperation. The baseline meteorological data set used to simulate snowcover is data of the observational network in Hydrometeorological Survey, Russia prepared for GAME project by Dr. V. Razuvaev of World Data Center, Prof. T. Ohata, and Dr. R. Suzuki of Frontier Research System for Global Change.

\section{Appendix}

\section{Empirical equation for snow albedo}

An empirical equation for snow albedo was presented based on the following facts: 1) albedo decreases exponentially after snowfall; 2) its rate decrease is large when air temperature is high (fast metamorphism); and 3) albedo of new snow, $A_{\max }$, is low for high temperatures and wet snow. One can estimate snow albedo from daily mean air temperature and precipitation as:

$$
\begin{aligned}
& A_{0}=A_{\max }, \\
& A_{n}=\left(A_{n-1}-A_{\min }\right) \exp (-1 / k)+A_{\min } .
\end{aligned}
$$

Here, $A_{n}$ : the snow albedo in $n$ days after the last snow fall, $A_{\text {min }}$ : minimum albedo set to 0.4 , and $k$ : a parameter defining decreasing rate of albedo. When daily-accumulated solid precipitation (using Eq.(25)) exceeds $3 \mathrm{~mm}$, albedo is reset as $A_{0}=$ 
$A_{\text {max }}$.

New snow albedo, $A_{\max }$, is obtained from daily mean air temperature, $T_{\text {mean }}$, as:

$$
\begin{aligned}
A_{\text {max }} & =-0.12 T_{\text {mean }}+0.76 \quad\left(T_{\text {mean }} \geq-1.0^{\circ} \mathrm{C}\right), \\
& =0.88 \quad\left(T_{\text {mean }} \leq-1.0^{\circ} \mathrm{C}\right) .
\end{aligned}
$$

The parameter, $k$, is:

$$
\begin{aligned}
k & =-4.9 T_{\text {mean }}+4.5 \quad\left(T_{\text {mean }} \leq 0.1^{\circ} \mathrm{C}\right), \\
& =4.0 \quad\left(T_{\text {mean }} \geq 0.1^{\circ} \mathrm{C}\right) .
\end{aligned}
$$

These two equations were obtained from albedo data in Sapporo, Japan (e.g., Kodama and Ishikawa 1988).

If snow cover is shallow, albedo decreases because of soil influence. Thus, albedo is modified with the following equation as:

$$
A^{\prime}=A-\left(A-A_{w e t}\right) \exp (-60 D),
$$

where $A_{w e t}$ is the wet soil surface albedo (assumed to be 0.18 ) and $D$ is snow depth (m).

\section{References}

Colbeck, S.C., 1983: Theory of metamorphism of dry snow. J. Geophys. Res., 88, 5475-5482.

Dickinson, R.E., 1984: Modeling evapotranspiration for three-dimensional global climate models. J.E. Hansen and T. Takahashi, Eds., Climate Processes and Climate Sensitivity, Geophysical Monograph, 29, Amer. Geophys. Union, Washington, DC, 58-72.

Fukami, H., K. Kojima and H. Aburakawa, 1985: The extinction and absorption of solar radiation within a snow cover. Annals of Glaciol., 6, 118122.

Fukuda, M. and T. Ishizaki, 1980: A simulation model for frost penetration beneath the ground on the basis of equilibrium surface temperatures. Seppyo. J. Japanese Soc. Snow and Ice, 42, 71-80, (in Japanese with English summary).

Fukuzawa, T. and E. Akitaya, 1991: An experimental study on the growth rates of depth hoar crystals at high temperature gradients (I). Low Temperature Science, Ser. A 50, 9-14, (in Japanese with English summary).

Hashimoto, T., T. Ohta, T. Toba, T.C. Maximov and A.V.Kononov, 2001: Heat and water balance characteristics of snowpack and permafrost during snowmelt season in a boreal forest over the Eastern Siberia. (in preparation).

Hiyama, T., T. Ohta, K. Suzuki and A. Sugimoto, 2001: Diurnal variation of surface energy fluxes and its impact on the lower atmospheric boundary layer over eastern Siberia. (submitted).
Kelliher, F.M., D.Y.Hollinger, E.-D. Schulze, N.N. Vygodskaya, J.N. Byers, J.E. Hunt, T.M. McSeveny, I. Milukova, A.Sogatchev, A. Varlargin, W. Ziegler, A. Arneth and G. Bauer, 1997: Evaporation from an eastern Siberian larch forest. Agric. For. Meteor., 85, 135-147.

Kodama, Y. and N. Ishikawa, 1988: Radiation measurements of snowy season in 1988 in Sapporo. Low Temperature Science, Ser. A 47 Data Report, 27-33, (in Japanese).

Kojima, K., 1956: Viscous compression of natural snow-layer II. Low Temperature Science, Ser. A 15, 117-135, (in Japanese with English summary). , 1957: Viscous compression of natural snow layers III. Low Temperature Science, Ser. A 16, 167-196, (in Japanese with English summary).

Kondo, J. and J. Xu, 1996: Effect of snow cover on the heat and water balance of bare soil surface in north-western China. Seppyo. J. Japanese Soc. Snow and Ice, 58, 303-316, (in Japanese with English summary).

and H. Yamazawa, 1986a: Bulk transfer coefficient over a snow surface. Boundary-layer $\mathrm{Me}$ teor, 34, 123-135.

and $1986 \mathrm{~b}$ : Measurement of snow surface emissivity. Boundary-layer Meteor., 34, 415-416.

, T. Nakamura and T. Yamazaki, 1991: Estimation of the solar and downward atmospheric radiation. Tenki, 38, 41-48, (in Japanese). , T. Watanabe, M. Nakazono and M. Ishii, 1992: Estimation of forest rainfall interception. Tenki, 39, 159-167, (in Japanese).

Lee, X., 1998: On micrometeorological observations of surface-air exchange over tall vegetation. Agric. For. Meteor., 91, 39-49.

- and T.A. Black, 1993: Atmospheric turbulence within and above a douglas-fir stand. Part II: eddy fluxes of sensible heat and water vapour. Boundary-layer Meteor., 64, 369-389.

Ohta, T., T. Hiyama, H. Tanaka, T. Kuwada, T.C. Maximov, T. Ohata and Y.Fukushima, 2001: Seasonal variation in the energy and water exchanges above and below a larch forest in eastern Siberia. Hydrological Processes, 15, 1459-1476.

Sellers, P.J., Y.Mintz, Y.C. Sud and A. Dalcher, 1986: A simple biosphere model ( $\mathrm{SiB}$ ) for use within general circulation models. J.Atmos. Sci., 43, 505-531.

Shinojima, K., 1967: Study on the Visco-Elastic deformation of deposited snow. H. Oura, Ed., Physics of Snow and Ice, Vol. I(2), Inst. Low. Temp. Sci. Hokkaido Univ., 875-907.

Sturm, M. and J.B. Johnson, 1992: Thermal conductivity measurements of depth hoar. J. Geophys. Res., 97, 2129-2139.

Sugaya, H., 1991: Distinguishing between rain and 
snow in cold season (3), predicting with wetbulb temperature. Preprints of the 1991 Conference Japanese Society of Snow and Ice, 212, (in Japanese).

Takata, K., 1998: Modeling the thermal and hydrological impacts of frozen ground on the climate system. Doctor's thesis, University of Tsukuba.

Takayabu, I., K. Takata, T. Yamazaki, K. Ueno, H. Yabuki and S. Haginoya, 2001: Comparison of the snow accumulation and the soil freezing processes among four land surface process models by using GAME/Tibet POP'97 data. J. Meteor. Soc. Japan, 79, 535-554.

Tanaka, H., 1999: Study on $\mathrm{CO}_{2}$ and $\mathrm{H}_{2} \mathrm{O}$ transfer processes in forest. Doctor's thesis, Kyoto University, (in Japanese).

Verma, S.B., D.D. Balocchi, D.E. Anderson, D.R. Matt and R.J.Clement, 1986: Eddy fluxes of $\mathrm{CO}_{2}$, water vapor, and sensible heat over a deciduous forest. Boundary-layer Meteor., 36, 71-91.

Verseghy, D.L., 1991: CLASS-A Canadian land surface scheme for GCMs, Part I: Soil model. Int. J. Climatol., 11, 111-133.
, N.A. McFarland and M. Lazare, 1993: CLASSA Canadian land surface scheme for GCMs, Part II: Vegetation model and coupled runs. Int. J. Climatol., 13, 347-370.

Yamazaki, T., 1998: A multi-layer heat balance model of snow cover adaptable to intensely cold regions. Seppyo. J. Japanese Soc. Snow and Ice, 60, 131141, (in Japanese with English summary).

, J. Kondo, T. Watanabe and T. Sato, 1992: A heat-balance model with a canopy of one or two layers and its application to field experiments. J. Appl. Meteor., 31, 86-103.

- - T.Sakuraoka, T. Nakamura and J. Kondo, 1993: A one-dimensional model of the evolution of snow-cover characteristics. Annals of Glaciology, 18, 22-26.

, B. Taguchi and J. Kondo, 1994: Estimation of the heat balance in a small snow-covered forested catchment basin. Tenki, 41, 71-77, (in Japanese).

Zhang, T., T.E. Osterkamp and K.Stamnes, 1996: Influence of the depth hoar layer of the seasonal snow cover on the ground thermal regime. Water Resour. Res., 32, 2075-2086. 